\title{
Late Quaternary climatic changes in the eastern Kumaun Himalaya, India as deduced from multi-proxy studies
} \author{
Chhaya Sharma ${ }^{3}$ \\ 1 Department of Geology, Kumaun University, Nainital, 263002, Uttarakhand, INDIA \\ 2 Birbal Sahni Institute of Palaeobotany, University Road, Lucknow, 226007, INDIA \\ 3 Department of Geology, Lucknow University, Lucknow, 226 007, INDIA \\ * For correspondence, email: bahadur.kotlia@gmail.com
}

Bahadur Singh Kotlia ${ }^{1 *}$, Jaishri Sanwal ${ }^{1}$, Binita Phartiyal ${ }^{2}$, Lalit Mohan Joshi ${ }^{1}$, Anjali Trivedi ${ }^{3}$ and

An event of neotectonic activity on an NE-SW trending subsidiary fault in the zone of E-W running intracrustal boundary thrust (South Almora Thrust) in the Champawat district of eastern Kumaun Himalaya resulted in creation of a lake at ca. 21.5 BP. The lake was drained out in the late Holocene leaving behind a $5.0 \mathrm{~m}$ thick sedimentary sequence of mostly black and carbonaceous mud indicating at the base a minor magnetic reversal between 20.5-19.7 ka BP. The profile, studied by using multi-proxies (e.g., carbon isotopes, pollen analysis, palaeo and mineral magnetism and clay minerals) has recorded globally well established abrupt climatic events in the last 20,000 years, such as, LGM, Older Dryas (OD), Younger Dryas (YD), Holocene warming, $8.2 \mathrm{ka}$ and $4.2 \mathrm{ka}$ events. Most events, estimated assuming the invariable rate of sediment accumulation for similar lithologies, may be related to the rapid changes in the local climate and albedo structure. We suggest that the ITCZ may have played a key role to control the behavior of south-west monsoon from LGM onwards. 